\title{
O discurso de violência simbólica em interações no Facebook sobre a participação feminina no cenário dos jogos eletrônicos de combate ${ }^{1}$
}

\author{
Graciele Urrutia Dias Silveira² \\ Programa de Pós-Graduação em Letras, Universidade Federal de Pelotas, Pelotas, RS, Brasil
}

Resumo: Este artigo tem como objetivo o estudo da violência simbólica de gênero presente nos discursos que fazem parte do contexto do jogo League of Legends e dos sites de redes sociais. $O$ intuito é discutir de que maneiras a violência se manifesta nas interações acerca da participação feminina nos jogos eletrônicos de combate a partir do estudo de seis publicações presentes em uma fanpage e em dois grupos no Facebook. Para esse fim, tais postagens foram analisadas à luz da Análise do Discurso Mediado por Computador (HERRING 2001; 2004), sendo considerados quatro níveis em cada uma delas: estrutura, sentido, interação e comportamento social. Dentre os resultados obtidos, foi possível compreender que a violência simbólica de gênero pode ser observada nas seguintes formas: interdição do discurso, estereótipos, insultos, assédio sexual e por culpabilizar as vítimas pelas agressões.

Palavras-chave: Violência simbólica; Gênero; League of Legends; Facebook; Discurso Mediado por Computador.

Title: The discourse of symbolic violence in interactions on Facebook about women's participation in combat electronic games

Abstract: This paper aims to study the symbolic violence which is targeted to the feminine gender through discourses that are part of the game League of Legends context and of social network websites. The objective is to discuss how violence is revealed by interactions concerning women's participation in electronic combat games via the study of six posts which were found on a fanpage and on two Facebook groups. With that purpose, such posts will be analyzed in the light of the Computer Mediated Discourse Analysis (HERRING, 2001; 2004) and four levels will be considered: structure, meaning, interaction and social behavior. Among the results, it was possible to comprehend that the gender symbolic violence can be observed in the following ways: speech interdiction, stereotypes, insults, sexual harassment and by blaming the victims for the aggressions.

Keywords: Symbolic violence; Gender; League of Legends; Facebook; Computer Mediated Discourse.

\footnotetext{
${ }^{1}$ Este artigo foi desenvolvido a partir da seleção de capítulos e seções presentes na dissertação de mestrado da mesma autora, intitulada "O discurso de violência simbólica de gênero em uma página e em grupos voltados ao League of Legends no Facebook". O referido trabalho foi conduzido sob a orientação da Professora Dra. Raquel Recuero, junto ao Programa de Pós-Graduação em Letras da Universidade Federal de Pelotas.

2 Doutoranda e Mestra em Letras pelo Programa de Pós-Graduação em Letras da Universidade Federal de Pelotas. Orcid: https://orcid.org/0000-0003-4087-0652

E-mail: gracidsilveira@gmail.com
} 


\section{Considerações iniciais}

Os primeiros jogos eletrônicos surgiram aproximadamente na década de 1960 com um jogo de tênis de mesa criado pelo físico William Higinbotham e, desde então, vêm ganhando destaque entre os mais diversos tipos de público (BARBOZA; SILVA, 2014). Tal popularização fica evidente em sites de redes sociais, ambientes nos quais há um número expressivo de grupos e páginas sobre games e, consequentemente, interações recorrentes a respeito do tema. O Facebook, por exemplo, permite que os gamers se apropriem das ferramentas oferecidas por ele, como postagens e comentários, a fim de debaterem assuntos como estratégias, preferências com relação a avatares, informações relacionadas a aspectos que não dominam, procura de companheiros para seus times etc. Em tais posts, podem ser observadas também interações em que é debatida a performance dos jogadores, inclusive a partir de uma perspectiva de gênero, em que o feminino é, comumente, apontado como inapto no que se refere aos jogos de combate.

Nesse sentido, culturalmente, atribuem-se qualidades aos homens como agressividade, inteligência, racionalidade, estratégia e liderança, características essenciais para o sucesso em videogames, principalmente com relação àqueles que envolvem estratégias para derrotar adversários em confrontos. Por outro lado, as meninas são representadas como não propensas a terem aptidão para os mesmos, já que elas seriam supostamente dotadas de fragilidade, característica considerada pelo senso comum como inerente ao gênero feminino (OLEGÁRIO, 2009). Levando em conta as ocorrências já mencionadas, o objetivo desse artigo é discutir como as mulheres são representadas em interações no Facebook sobre a participação feminina nos jogos de combate, sobretudo no jogo League of Legends. Para este fim, haverá uma breve discussão sobre aspectos teóricos indispensáveis à compreensão dos dados levantados; a seguir, será apresentada a metodologia que serviu como base para a análise das amostras encontradas no site de rede social em questão e, então, haverá discussão acerca delas.

\section{Discurso e Poder}

A partir de uma análise baseada nas ideias defendidas pelo filósofo Michel Foucault, sobretudo em sua obra $A$ ordem do discurso (2014), o discurso pode ser entendido como um instrumento de extrema importância no que diz respeito às relações de poder presentes na sociedade. Segundo o autor, o discurso é "aquilo por que, pelo que se luta, o poder do qual queremos nos apoderar" (FOUCAULT, 2014, p. 10); isto é, ele é almejado, pois por meio dele é possível não somente dar ordens, mas também estabelecer e reafirmar verdades sobre as coisas e grupos de pessoas. Stolz (2008) explica tal ideia de Foucault por dizer que há uma luta em torno da posse do discurso no sentido de que quem se apodera dele, consequentemente, obtém poder e pode, por sua vez, instaurar relações assimétricas entre 
quem o profere e o ouve. Desse modo, os homens, por exemplo, que possuem uma posição, de modo geral, favorável nas relações de poder, podem reproduzir ideias que inferiorizam as mulheres como as de que elas devem ficar restritas a atividades domésticas, assegurando, desse modo, que esses continuem a ter destaque em cenários como o mercado de trabalho e jogos eletrônicos de combate, por exemplo.

Pierre Bourdieu também considera o discurso sob a ótica das relações de poder e traz alguns conceitos importantes sobre o tema em sua obra Poder Simbólico (1989). O primeiro conceito importante trazido à tona pelo pesquisador recebe o mesmo nome desse trabalho e é definido como "poder quase mágico que permite obter o equivalente daquilo que é obtido pela força (física ou econômica), graças ao efeito específico de mobilização" (p. 14). Além disso, Bourdieu acrescenta que o poder simbólico torna possível "constituir o dado pela enunciação, de fazer ver e fazer crer, de confirmar ou de transformar a visão do mundo e, deste modo, a ação sobre o mundo, portanto o mundo" (p. 14). Portanto, pode-se compreender que o termo em questão designa o efetivo exercício do poder por meio do uso da linguagem.

O autor prossegue a obra explicando questões importantes em relação ao conceito de poder simbólico e afirma que relações hierárquicas são determinantes na interação a ponto de elas interferirem em estratégias retóricas da conversação como quem pode cortar a palavra, fazer perguntas e devolver perguntas, falar por muito tempo sem ser interrompido etc. A interação, portanto, para o pesquisador, funciona como uma espécie de mercado linguístico em que alguns são considerados excluídos ou com baixa taxa de representatividade devido a questões como sexo, idade, estudos etc. Desse modo, na visão de Bourdieu, a imposição de uma visão de mundo está proporcionalmente ligada ao capital simbólico, ou reconhecimento que o locutor recebe dentro de um grupo.

Bourdieu (1989; 1991) também trata da questão de como algumas condutas acabam por ser normalizadas por meio do discurso. Em "Poder Simbólico", o autor traz o assunto à atenção e afirma que realidades pré-construídas por meio do discurso acabam por ficar como que inscritas nas coisas e no cérebro e passam, consequentemente, a ser percebidas como evidentes e perfeitamente naturais. Almeida (2005) explica a questão da naturalização do discurso por afirmar que ela ocorre por meio de uma ação pedagógica, i.e., um processo de inculcação, a fim de formar o habitus do indivíduo de acordo com os interesses da cultura dominante.

Tal ação pedagógica, por sua vez, tem a sua eficácia proporcional ao prestígio da instituição ou da pessoa envolvida no processo de inculcação, além de sustentar-se em um processo de dissimulação. O processo de dissimulação tem um papel importante na naturalização do discurso, segundo a autora, porque à medida que um indivíduo não percebe que está sendo construído como inferior por meio do discurso de outra pessoa é mais improvável que ele questione esse discurso e, consequentemente, passe a considerá-lo como um regime de verdade. 


\title{
Violência simbólica
}

Slavoj Zizek aborda a questão da violência em "Violência: seis reflexões laterais" (2014), por afirmar que ela pode assumir formas distintas. A primeira maneira é a violência subjetiva, aquela mais visível aos olhos, expressa por meio de crimes e confrontos civis, por exemplo, sendo, para o autor, de fácil identificação. A seguir, o pesquisador trata do que chama de violência objetiva, não tão perceptível, e que compreende dois aspectos - a violência simbólica e a sistêmica - e as define da seguinte maneira:

\begin{abstract}
Em primeiro lugar, há uma violência "simbólica" encarnada na linguagem [...] essa violência não está em ação apenas nos casos evidentes - e largamente estudados de provocação e de relações de dominação social que nossas formas de discurso habituais reproduzem: há uma forma ainda mais fundamental de violência que pertence à linguagem enquanto tal, à oposição de um certo universo de sentido. Em segundo lugar, há aquilo que eu chamo violência "sistêmica", que consiste nas consequências muitas vezes catastróficas do funcionamento regular de nossos sistemas econômico e político. (ZIZEK, 2014, p. 17)
\end{abstract}

A partir da afirmação acima e de explicações posteriores dadas por Zizek (op. cit.), pode-se inferir que as explosões de violência tidas como "irracionais" são motivadas por uma violência objetiva, invisível, que pode ocorrer por meio da máquina estatal (sistêmica) ou por meio do discurso (simbólica). A figura a seguir ajuda a entender como se dá a divisão entre a tida como visível e a invisível.

Figura 1- Pirâmide da sociedade patriarcal

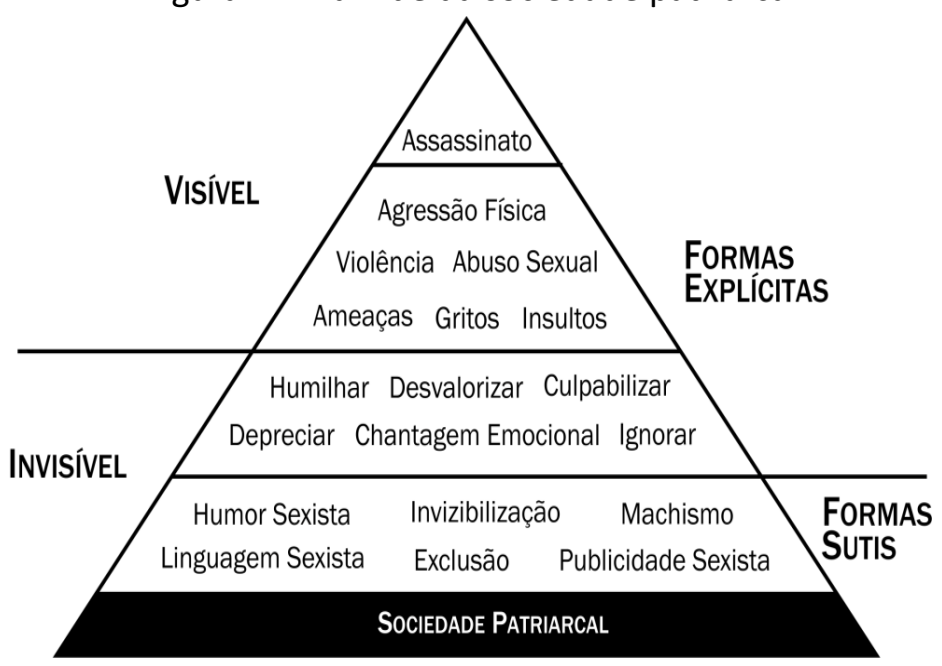

Fonte: Viegas e Recuero (2014).

A partir da pirâmide da sociedade patriarcal (figura 1), pode-se inferir que atitudes como humilhar, depreciar e desvalorizar outra pessoa podem ser consideradas como violência simbólica (VIEGAS; RECUERO, 2014); aspecto fulcral neste trabalho e que, embora 
não deixe marcas físicas, pode ter impactos indesejados, como a manutenção de estereótipos relacionados à sexualidade e também a gênero.

Bourdieu (1989) aborda ainda a questão da violência simbólica, tratando-a como um instrumento de dominação por parte daqueles que detêm poder simbólico sobre outros. Segundo ele,

\begin{abstract}
sistemas simbólicos cumprem a sua função política de instrumentos de imposição ou legitimação da dominação, que contribuem para assegurar a dominação de uma classe sobre outra (violência simbólica), dando o reforço da sua própria força às relações de fora que as fundamentam e contribuindo, assim, segundo a expressão de Weber, para a 'domesticação dos dominados'. (p. 11)
\end{abstract}

A linguagem, a ciência, a religião, entre outros sistemas simbólicos, por conseguinte, são considerados por Bourdieu como meios de impor ideias e conceitos a pessoas que estão em uma posição desprivilegiada nas relações de poder e, conforme o próprio autor esclarece na citação acima, permitem o exercício da violência simbólica, isto é, a dominação de uma determinada classe. Ainda sobre o exercício de tal forma de violência, Bourdieu (1991, p. 152) afirma que ela tem como base o não reconhecimento por parte daqueles que a sofrem, logo, as vítimas tendem a não se entender como tais e tampouco percebem o ocorrido como violência. Exemplo desse não reconhecimento fica evidente em publicações em grupos direcionados ao humor na internet cujo assunto é o gênero feminino, pois, inclusive, mulheres curtem e compartilham com seus seguidores publicações que legitimam estereótipos (RECUERO; SOARES, 2013).

Com base nos conceitos apresentados tanto por Zizek (2008) quanto por Bourdieu (1989; 1991), pode-se inferir que eles apresentam similaridades no sentido de que a violência simbólica é algo invisível ou não reconhecido, isto é, ela está naturalizada nas relações sociais por meio de um processo histórico. Desse modo, a violência exercida por meio do discurso pode estar presente em situações cotidianas e ser considerada como natural à medida que as ideias ofensivas de um grupo dominante acabam por ser legitimadas. Por exemplo, se alguém critica um menino dizendo que ele joga como uma menina, a intenção é claramente de ofender o indivíduo, no sentido de dizer que ele não teria habilidade suficiente para ser bem-sucedido no jogo, da mesma maneira que uma menina naturalmente não teria (FRAGOSO et al., 2017) Ou, ainda, se alguém afirma que mulheres não têm a mesma aptidão para dirigir um carro que um homem teria, essa pessoa também ofende o gênero feminino e reforça o estereótipo construído historicamente acerca das habilidades que pessoas desse gênero possuem.

\title{
Jogos, mídias sociais e violência de gênero
}

As questões de violência simbólica e de construções históricas que se naturalizaram no que diz respeito à identidade de determinados grupos estão diretamente relacionadas às 
representações que tratam o gênero feminino como inferior em relação ao masculino ${ }^{3}$. Bourdieu trata sobre o assunto em sua obra Dominação Masculina (1998) e afirma que essas construções em que o homem é visto como superior à mulher têm bases biológicas, isto é, o falo seria um símbolo da virilidade masculina, de aptidão e habilidades cognitivas para o trabalho, enquanto a mulher, portadora de um "falo invertido", teria uma posição de dependência. Sobre essa questão o autor afirma que

a diferença biológica entre os sexos, isto é, entre o corpo masculino e o feminino, e, especificamente, a diferença anatômica entre os órgãos sexuais, pode assim ser vista como justificativa natural da diferença construída entre os gêneros e, principalmente, da divisão social do trabalho (BOURDIEU, 1998, p. 20)

Desse modo, quando o autor se refere às diferenças biológicas, ele não as trata como fator único de diferenciação entre homens e mulheres; antes, tais diferenças são percebidas como um gatilho para posteriores construções acerca do que se espera de cada gênero. Sobre o tema, Scott (1995) explica que, ao tratar das diferenças entre os sexos, é importante pensar no termo "gênero" e no que esse implica, pois ele evoca justamente as construções sociais que definem que papéis são esperados dos indivíduos nascidos com o sexo masculino. Tais expectativas, por sua vez, são construídas a partir de crenças e valores e delimitam as relações de poder no sentido de que papéis e espaços são ocupados por mulheres e homens em determinados contextos.

Nesse sentido, a própria história das mulheres ajuda a compreender como determinadas construções acerca do gênero feminino e da sua função na sociedade surgiram e, em alguns casos, ainda se mantêm. Michelle Perrot, em Minha História das Mulheres (2017), esclarece que, durante um longo período de tempo, as mulheres foram mantidas na invisibilidade devido a terem estado confinadas em casa, cuidando da família em silêncio, sendo esse o estado natural das coisas então. Com relação aos discursos sobre elas, a autora explica que filósofos como Aristóteles refletiam o pensamento de sua época com relação à superioridade masculina. Segundo Perrot, para ele, as mulheres eram uma ameaça potencial para o coletivo, sendo necessário mantê-las afastadas já que lhes faltava alguma coisa, sendo assim, defeituosas. O papel delas passava, portanto, a se restringirem a ser "um bom receptáculo" (PERROT, 2007, p. 23).

Com o passar dos anos, alguns eventos, no entanto, abrem brechas nos sistemas de poder, como as revoluções do século XX e movimentos feministas, dando espaço para as francesas, por exemplo, em 1944, ganharem direito ao sufrágio universal. As guerras também permitiram que, com a saída dos homens para os campos de combate, as mulheres

\footnotetext{
${ }^{3}$ Embora neste trabalho sejam mencionadas expressões como gênero feminino e masculino e homem e mulher, entende-se que as identidades vão além de binarismos, conforme os pressupostos da Teoria Queer, que esclarece que os sujeitos e as práticas sexuais vão além de oposições como homossexual/heterossexual, mulher/homem, mas que apresentam uma variedade e diversidade de subjetivações e práticas (PINO, 2007), como bissexualidade, a transgeneridade, entre outras.
} 
assumissem posições tipicamente masculinas, como conduzir arados e bondes, trabalhar e ocupar o espaço público (PERROT, 2017). Até os dias de hoje, o exercício de atividades consideradas como relacionadas ao gênero masculino vêm sendo assumidas cada vez mais pelo gênero feminino, como no caso da tomada de posições de liderança em grandes corporações e na política, além da participação em outros universos tipicamente relacionados aos homens, como o caso dos jogos eletrônicos de combate.

No entanto, apesar dos grandes avanços que implicam em progresso às mulheres, resquícios dessa história que privilegiou o masculino em detrimento do feminino permanecem, sendo esses normalizados nas relações sociais a ponto de não serem percebidos sequer pelas vítimas. Reafirmando as ideias apresentadas em Language and Symbolic power (1991, p. 152), sobre a não percepção dos dominados com relação à violência simbólica imposta por parte dos dominadores devido a um processo de naturalização de construções históricas, Bourdieu (1998) diz que a primazia dada ao gênero masculino está inscrita no habitus e, portanto, funciona como uma matriz para posteriores pontos de vista, pensamentos e ações acerca de supostas diferenças com relação às capacidades de pessoas pertencentes aos gêneros masculino e feminino. Visto tais construções feitas por meio do discurso acabar por ser tidas como naturais, os indivíduos do gênero feminino, desse modo, tendem a não as considerar como violência e tê-las como normais, parte do status quo.

Com relação aos papeis do gênero feminino em determinados contextos, do mesmo modo como ocorre na esfera do mercado de trabalho, em que há um senso comum, uma ideia naturalizada de que certas profissões devem ser exercidas por mulheres e outras por homens, acontece algo similar quando a questão são jogos online. Culturalmente, atribuemse aos homens qualidades essenciais ao sucesso em videogames, como agressividade, inteligência, racionalidade, estratégia e liderança, principalmente, com relação àqueles que envolvem estratégias para derrotar adversários em confrontos, enquanto as meninas são tidas como não propensas a terem aptidão para os mesmos, já que seriam supostamente dotadas de fragilidade, característica considerada pelo senso comum como inerente ao gênero feminino (OLEGÁRIO, 2009).

No que se refere a esse tipo de representação, Cross (2014) afirma que há uma imposição de significados e narrativas por parte significativa de jogadores do gênero masculino, o que inclui a ideia de que as mulheres que participam dos mesmos jogos que eles, provavelmente, não são belas, não têm capacidade para lidar com computadores e estratégias ou ainda são feminazis, termo usado para se referir de modo negativo a feministas, dando a entender que elas são radicais e têm por objetivo causar problemas. Segundo a autora, esse tipo de narrativa evidencia a ideia naturalizada de que os homens teriam um capital simbólico com relação às mulheres no sentido de que eles teriam mais facilidade para lidar com tecnologias e mais habilidades com os games.

Outros aspectos que evidenciam violência simbólica de gênero com relação a videogames são: a pequena quantidade de personagens femininas, a imagem estereotipada 
delas quando aparecem e o fato de haver um mercado específico para as meninas que exclui jogos que envolvem confrontos, corridas de carro, por exemplo. Cassel e Jenkis (2000) afirmam que resultados de pesquisa relacionada a videogames fornecem um exemplo claro de como ocorre a construção social de gênero, visto que as mulheres raramente aparecem neles, exceto nos casos em que donzelas pedem resgate ou servem como recompensa por uma missão ter sido finalizada com sucesso.

Segundo as autoras, essa construção que envolve o universo dos games também está presente em jogos voltados especificamente ao público feminino, porque, ao invés de criarem um ambiente menos desigual, reforçam velhos estereótipos. Por meio de uma breve pesquisa no site de busca Google é possível encontrar diversas plataformas desenvolvidas especificamente para meninas e nelas verificar o que as autoras afirmam, pois tais jogos voltados ao público feminino, em sua maior parte, têm o design gráfico construído com tons de cor-de-rosa (cor delicada, atribuída como símbolo do gênero feminino) e como tema principal o culto à beleza (maquiagem e experimentação de roupas), compras, cuidados com a casa e os filhos e relacionamentos amorosos, conforme apresentado na imagem a seguir.

Figura 2 - Jogos voltados a meninas

\section{Jogos de Meninas}
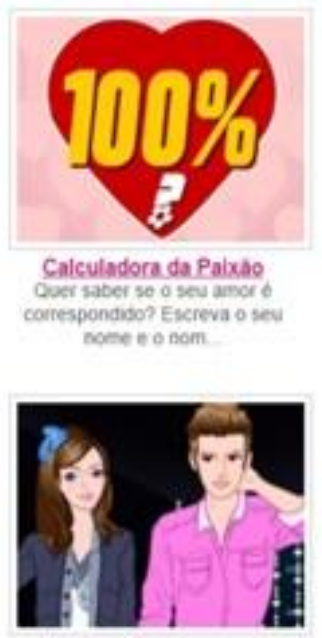

Vestir a Menina Dara e Encentro
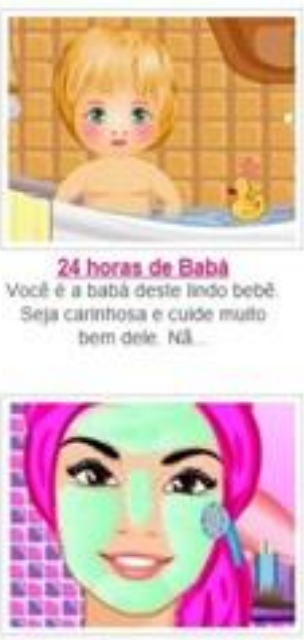

Selena Gomez ne Salà de Beleza

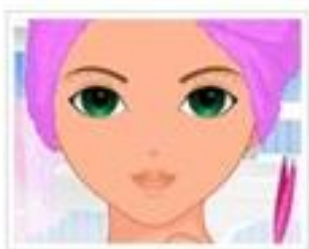

Transformacalo da Menina Nerd Esta garota é uma nerd e nalo
mostra a sua veidadeka beicza.

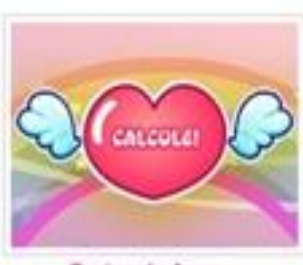

Testes de Amer Pinrtase com etse 1090 chew of

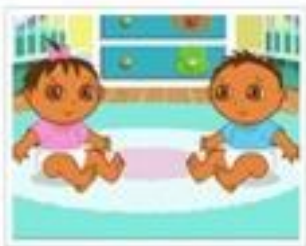

Dera a Babs

Dora a Exploradora iem qoe gémeos Aluoba a a taze.

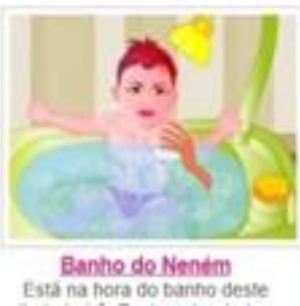

Fonte: http://www.clickjogos.com.br/jogos-de-meninas/. Acesso em 18 nov. 2017

Com relação à representação gráfica estereotipada do gênero feminino em jogos de videogame, Rodrigues e Santos (2014) afirmam que a mulher, quando tem certa representatividade entre os personagens de jogos de ação, por exemplo, ela parece ser apresentada de acordo com um suposto padrão feminino ideal: seios e glúteos fartos, cintura com curvas bem marcadas, cabelos longos e lisos. As autoras, em sua pesquisa, 
fazem uma análise mais profunda das imagens das personagens do jogo League of Legends 4 e encontram essas mesmas características, assim como verificaram que, dentre 117 personagens, apenas 40 eram femininas e que $65 \%$ dessas apresentavam algum grau de nudez ou roupas justas que delineassem o contorno de seus corpos.

\section{Procedimentos de coleta}

A fim de compreender como a violência simbólica de gênero se manifesta em conversações no Facebook sobre a participação feminina nos jogos de combate, sobretudo no League of Legends, foram escolhidas - como objeto de análise - postagens que fazem referência ao assunto e também comentários que discutem o conteúdo de tais publicações. Durante o período de julho de 2017 a fevereiro de 2018, foram monitoradas as fanpages League of Legends - Brasil' ${ }^{5}$, League of Legends - Denúncia ${ }^{6}$, Liga do Lag $^{7}$ e os grupos fechados Rexpeita Elas - League of Legends ${ }^{8}$, League of Legends Brasil ${ }^{9}$ e League of Legends - Brasil10.

Dentre os grupos e fanpages, foram monitoradas 2773 publicações e seis foram selecionadas (quadro 1): uma da fanpage Liga do Lag, três do grupo League of Legends Brasil e duas do League of Legends - Brasil por nelas haver número suficiente de comentários com conteúdo que permitisse o estabelecimento de um debate mais profundo sobre a questão da violência simbólica de gênero. Além disso, serviram como parâmetro de escolha a participação de homens e mulheres nas discussões, a fim de pesquisar como os dois lados se posicionavam a respeito de estereótipos e insultos relacionados ao gênero feminino e a ocorrência de comentários tanto favoráveis quanto desfavoráveis a discursos estigmatizadores e xingamentos. A página League of Legends Brasil foi desconsiderada por não apresentar conteúdo tóxico e a League of Legends - Denúncia devido a não apresentar nenhuma publicação no período de observação. As publicações sobre gênero no Rexpeita elas não foram selecionadas por não haver comentários nelas e as cinco restantes nos grupos League of Legends Brasil e League of Legends - Brasil devido a não atenderem os parâmetros acima mencionados

\footnotetext{
${ }^{4}$ https://br.leagueoflegends.com/pt/. Acesso em 01 set 2019.

${ }^{5}$ https://www.facebook.com/LeagueofLegendsBrasil/.

${ }^{6}$ https://www.facebook.com/loldenuncia/.

${ }^{7}$ https://www.facebook.com/Liga-do-Lag-1963254740571203/.

${ }^{8}$ https://www.facebook.com/groups/rexpeitaelas/?ref=br_rs.

${ }^{9}$ https://www.facebook.com/groups/197360944012804/.

${ }^{10}$ https://www.facebook.com/groups/1430214993879690.
} 
Quadro 1 - Publicações analisadas

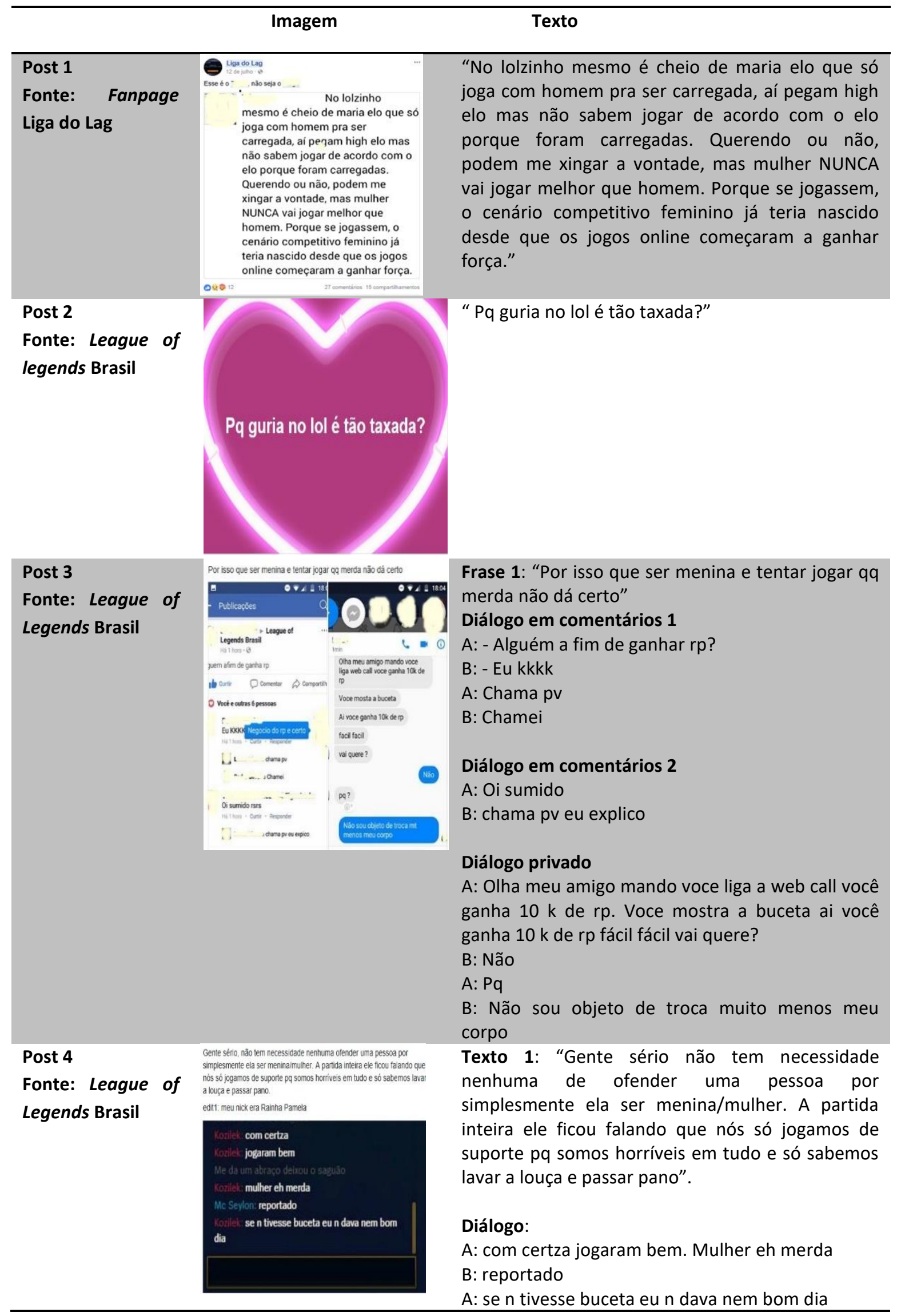




\begin{tabular}{|c|c|c|}
\hline $\begin{array}{l}\text { Post } 5 \\
\text { Fonte: League of } \\
\text { Legends-Brasil }\end{array}$ & 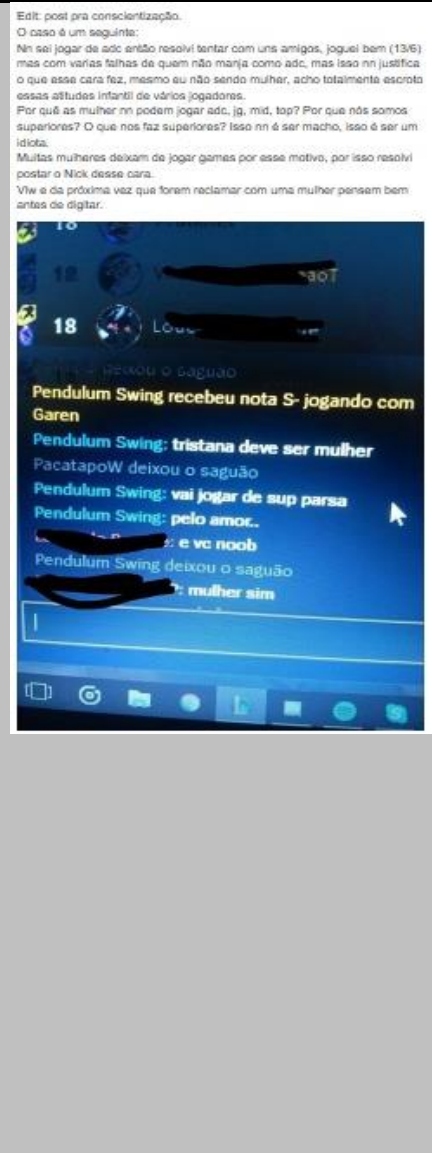 & $\begin{array}{l}\text { Texto 1: } \\
\text { "Edit: post pra conscientização. O caso é um } \\
\text { seguinte: nn sei jogar de adc então resolvi jogar } \\
\text { com uns amigos, joguei bem (13/6), mas com várias } \\
\text { falhas de quem não manja como adc, mas isso nn } \\
\text { justifica o que esse cara fez, mesmo eu não sendo } \\
\text { mulher, acho totalmente escroto essas atitude } \\
\text { infantil de vários jogadores. } \\
\text { Por quê as mulher nn podem jogar de adc, jg, mid, } \\
\text { top? Por que nós somos superiores? O que nos } \\
\text { faz superiores? Isso nn é ser macho, isso é ser um } \\
\text { idiota. } \\
\text { Muitas mulheres deixam de jogar games por esse } \\
\text { motivo, por isso eu resolvi postar o nick desse cara. } \\
\text { Vlw e da próxima vez que forem reclamar com uma } \\
\text { mulher pensem bem antes de digitar." } \\
\text { Texto 2: } \\
\text { Pendulum Swing recebeu nota } 5 \text { jogando com } \\
\text { Garen. } \\
\text { Pendulum Swing: Tristana deve ser mulher } \\
\text { PacatapoW deixou o saguão } \\
\text { Pendulum Swing: vai jogar de main sup parsa... } \\
\text { pelo amor. } \\
\text { B: e vc noob } \\
\text { Pendulum Swing deixou o saguão } \\
\text { C: mulher sim }\end{array}$ \\
\hline $\begin{array}{l}\text { Post } 6 \\
\text { Fonte: League of } \\
\text { Legends Brasil }\end{array}$ & 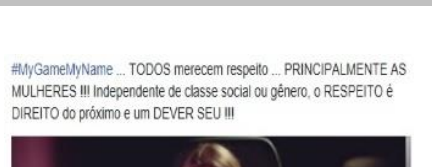 & $\begin{array}{l}\text { "\#MyGameMyName...TODOS merecem respeito... } \\
\text { PRINCIPALMENTE AS MULHERES!!! Independente } \\
\text { de classe social ou gênero, o RESPEITO é direito do } \\
\text { próximo e um DEVER SEU!!!"11 }\end{array}$ \\
\hline
\end{tabular}

É importante ressaltar que em tais postagens e comentários que serão apresentados no decorrer dessa pesquisa são observadas questões éticas; portanto, houve a preocupação de que o nome e a foto de perfil utilizada pelos indivíduos responsáveis pelas trocas interacionais analisadas tenham sido preservadas por meio do apagamento destes nos exemplos coletados.

\footnotetext{
${ }^{11} \mathrm{O}$ vídeo que faz parte da publicação contém frases frequentemente dirigidas a mulheres em jogos, como: "Seu lugar é na cozinha, fique lá", "Sua puta! Sua prostituta! Eu vou comer seu ***”, entre outras. Há no vídeo também referência à campanha divulgada nas mídias sociais \#MyGameMyName, que denuncia tal tipo de atitude e o fato de mulheres terem de se proteger desse tipo de agressões usando nicknames masculinos durante as partidas. Endereço do vídeo e mais informações sobre a campanha: http://ow.ly/Akqf30i06Az. Acesso em 20 fev. 2018.
} 


\section{Metodologia}

No que se refere à metodologia utilizada para a investigação, teve-se como base a Análise de Discurso Mediada por Computador (HERRING, 2004), que utiliza conhecimentos de diferentes áreas a fim de investigar comportamentos que são postos em prática por meio do discurso em ambientes online. Diversos fenômenos relacionados à comunicação mediada por computador podem ser analisados pela CMDA. Entre eles, os de nível micro, como processos de formação de palavras, escolha lexical, estrutura de frases e os de nível macro, como a coerência textual, questões de igualdade de gênero e identidade, que são levantados por meio do discurso. São quatro os domínios ou níveis de linguagem analisados: 1) estrutura, 2) significado, 3) interação e 4) comportamento social.

Quadro 2 - Os quatro níveis da CMDA

\begin{tabular}{|c|c|c|c|}
\hline Níveis & Questões & Fenômeno & Métodos \\
\hline Estrutura & $\begin{array}{l}\text { Oralidade, formalidade, } \\
\text { eficiência, } \\
\text { expressividade, } \\
\text { complexidade, } \\
\text { características de gênero } \\
\text { etc. }\end{array}$ & $\begin{array}{lr}\text { Tipografia, } & \text { ortografia, } \\
\text { morfologia, } & \text { sintaxe, } \\
\text { esquema do } & \text { discurso, } \\
\text { convenções } & \text { de } \\
\text { formatação. } & \end{array}$ & $\begin{array}{l}\text { Linguística estrutural e } \\
\text { descritiva, análise de } \\
\text { texto, corpus linguístico, } \\
\text { estilística. }\end{array}$ \\
\hline Sentido & $\begin{array}{l}\text { O que é pretendido } \\
\text { O que é comunicado } \\
\text { O que é alcançado }\end{array}$ & $\begin{array}{l}\text { Significado das palavras, } \\
\text { atos de fala, trocas. }\end{array}$ & Semântica, pragmática \\
\hline Interação & $\begin{array}{lr}\text { Interatividade, } & \text { tempo, } \\
\text { coerência, reparação, } & \text { como } \\
\text { interação } & \text { construção. }\end{array}$ & $\begin{array}{l}\text { Turnos, sequências, } \\
\text { trocas etc. }\end{array}$ & $\begin{array}{l}\text { Análise da conversação, } \\
\text { etnometodologia. }\end{array}$ \\
\hline $\begin{array}{l}\text { Comportamento } \\
\text { Social }\end{array}$ & $\begin{array}{l}\text { Dinâmica social, poder, } \\
\text { influência, identidade, } \\
\text { comunidade, diferenças } \\
\text { culturais etc. }\end{array}$ & $\begin{array}{l}\text { Expressões linguísticas } \\
\text { de status, conflito, } \\
\text { gerenciamento da face, } \\
\text { jogos, discurso. }\end{array}$ & $\begin{array}{l}\text { Sociolinguística } \\
\text { interacional, análise } \\
\text { crítica do discurso, } \\
\text { etnografia } \\
\text { comunicação. }\end{array}$ \\
\hline
\end{tabular}

Fonte: Herring (2004).

A estrutura está relacionada à ortografia, à formação de palavras e à configuração das frases, enquanto o significado compreende o sentido de palavras, frases e outras unidades maiores. No que se refere à interação, ela inclui a tomada de turnos, desenvolvimento de tópicos e outros meios de negociar as trocas interacionais e o último nível, o comportamento social, relaciona-se a expressões linguísticas de conflito, poder e pertencimento a um grupo, entre outras (HERRING, 2004). Desse modo, as seis publicações foram analisadas sob esses quatro níveis, sendo que a seção a seguir trará discussões acerca do que foi observado especialmente na seção interação, que traz exemplares dos comentários feitos nas postagens. 


\section{Análise dos dados e discussão}

A análise das seis publicações selecionadas permite compreender que a violência de gênero pode se manifestar nas interações entre participantes de páginas e grupos sobre o jogo League of Legends ao menos de cinco maneiras. A primeira dessas manifestações em termos de número de ocorrências foi a questão da interdição do discurso feminino de lutas, em que as mulheres que denunciaram as agressões foram representadas nas conversações estabelecidas por meio dos comentários da fanpage Liga do Lag e nos grupos League of Legends - Brasil como desequilibradas e extremamente sensíveis; portanto, não dignas de serem levadas em conta. Sendo assim, há uma luta pela "posse do discurso", em que os responsáveis pelas ofensas às jogadoras, tal qual acontece com o "discurso do louco" (FOUCAULT, 2014), buscam evidenciar que as mesmas, por suas condições psicológicas, não merecem que suas palavras sejam acolhidas e tidas como verdade. Esse tipo de conduta pode ser observado nas interações em todas as postagens e uma amostra pode ser observada na figura 3, onde se lê: “[...] tem que fazer post sendo a vítima, isso é praq? para que sintam pena de você ou para ganhar atenção? ou as duas coisas".

Figura 3 - Participante do grupo League of Legends - Brasil acusando jogadoras de se "vitimizarem" no Facebook

Só que muitas garotas tiram print, vem desabafar e bla bla bla, mas não sabe muta e continuar jogando, tem que fazer post sendo a vatíma, isso é praq? para que sintam pena de você u para ganhar atenção? ou as duas coisas?

Fonte: Acervo pessoal, retirado do Facebook.

Observa-se, neste caso, que o responsável pela afirmação na figura 3 usa o seu poder simbólico (BOURDIEU, 1991) no contexto dos jogos de combate para convencer os demais participantes dos comentários de que aquelas que denunciam ofensas, na verdade, não teriam razão no que dizem e que seus objetivos seriam chamar atenção para si mesmas e se fazerem passar por vítimas. Tais representações acerca das mulheres como exageradas e extremamente sensíveis buscam interditar o discurso delas e são consideradas como violência, neste trabalho, pois buscam desvalorizar e depreciar o que as mesmas dizem (VIEGAS; RECUERO, 2014), além de tal conduta ser uma forma de tentar calar a voz delas e de continuar impondo significados que mantêm o gênero masculino em uma posição de dominação nas relações de poder (BOURDIEU, op. cit.).

A segunda forma de manifestação de violência encontrada de modo mais frequente nas publicações analisadas foram os estereótipos. Tais construções preconcebidas podem ser encontradas nas interações em todas as postagens e manifestam-se por meio de um discurso que afirma que as mulheres têm habilidade inferior à dos homens com relação a 
jogos de combate. Esse discurso encontrado nos dados analisados está em consonância com a pesquisa de Olegário (2009) e Cross (2014), que apontam que, no contexto dos games, o gênero feminino é representado por parte da comunidade como inapto, pois as jogadoras, de modo geral, não teriam habilidade para lidar com computadores e estratégias e que, por isso, deveriam se manter afastadas de games como o League of Legends ou restritas a posições consideradas como de menos destaque como a de suporte, por exemplo.

Alguns ainda afirmam que jogadoras high elo, com um nível de desempenho mais alto, só chegaram a essa posição, pois tiveram ajuda de homens e que o gênero feminino como um todo deveria se manter restrito a papéis tipicamente atribuídos às mulheres em uma sociedade patriarcalista como o de ater-se aos serviços domésticos e o de gerar filhos, repetindo, desse modo, papéis que essas vêm lutando para desconstruir ao longo da história, de acordo com Perrot (2017). Tal modo de pensar fica evidente em comentários como "menina só presta pra reproduzir" (figura 4), "mulher só presta pra limpar a casa" (figura 5), conforme pode ser observado abaixo.

Figura 4- Exemplo de estereótipo de gênero

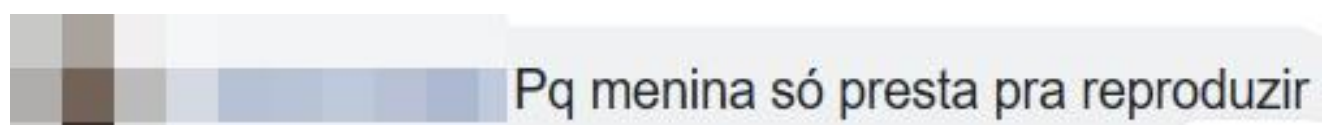

Fonte: Acervo pessoal, retirado do Facebook.

Figura 5 - Exemplo de estereótipo de gênero

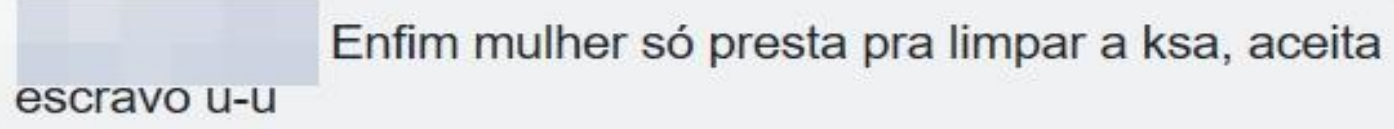

Fonte: Acervo pessoal, retirado do Facebook.

Entende-se que tal modo de manifestação de violência foi observado repetidas vezes devido ao discurso que reitera estereótipos serem uma forma "invisível" de violência (ZIZEK, 2008) e, muitas vezes, não percebidos como agressão por serem considerados uma verdade, uma construção naturalizada por meio da imposição de significados por parte de quem detém o poder. Sendo percebidos como uma verdade, parte do status quo, por muitos, inclusive dos oprimidos, conforme observado por Bourdieu (1989), tal discurso sofre menos retaliações e acaba por se difundir com mais força nas mídias sociais.

Em terceira posição, foram encontradas amostras de culpabilização de quem sofre com o problema. Exemplos de tal manifestação podem ser encontrados em comentários em que as meninas são representadas como responsáveis pelos xingamentos que sofrem durante as partidas, já que estas, supostamente, não se dedicariam ao jogo. Ainda há aqueles que acusam as participantes de provocarem a ira dos gamers do gênero masculino e, desse modo, merecerem retaliação. Além disso, na publicação 3 , quando um rapaz 
oferece pontos no jogo em troca de fotos nuas e a menina denuncia no grupo League of Legends Brasil, um dos participantes do grupo tira a atenção da atitude lamentável do agressor, culpabilizando a menina pela violência sofrida com as seguintes palavras: "2017 e tu acredita em rp grátis, dá nisso" (figura 6), conforme ser observado na imagem abaixo.

Figura 6 - Comentário que responsabiliza a vítima da violência simbólica pelo ocorrido

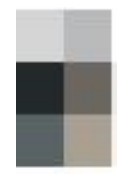

\section{7 e tu acredita em rp grátis, da nisso}

Fonte: Acervo pessoal, retirado do Facebook.

Essa atitude pode ser atribuída a uma ideia naturalizada através do discurso (BOURDIEU 1989; 1991) de que os homens, quando assediam mulheres, não estão fazendo nada inadequado e sim algo que é próprio do gênero masculino, isto é, estão expressando sua virilidade; portanto, cabendo a elas apenas entender a proposta e mostrar sua recusa caso não tenham interesse. O entendimento da atribuição de culpa às vítimas pelos estereótipos, assédio e agressão direcionados ao gênero feminino como uma forma sutil e invisível de violência está em consonância com a pirâmide da sociedade patriarcal (figura 1), encontrada no artigo de Viegas e Recuero (2014).

Em quarto lugar, por ordem de frequência de amostras, estão os insultos, sobretudo com relação à aparência e conduta das jogadoras quando essas, por alguma razão, têm um mau desempenho em uma partida. Exemplos disso podem ser encontrados em um comentário (figura 7) em que uma menina relata ter sido insultada diversas vezes e, inclusive, chamada de "resto de aborto", expressão usualmente utilizada para ofender a aparência de alguém.

Figura 7 - Relato de insultos em um jogo eletrônico de combate

Já sofri muito isso em lol. Já fui chamada de resto de aborto, se queria leite ( sabemos o que se referiram). Uma menina em uma partida, disseram que deveria ser estuprada.

Fonte: Acervo pessoal, retirado do Facebook.

Tais tipos de insultos observados neste trabalho encontram amparo na pesquisa de autores como Kurtz (2015), que afirma que comumente as jogadoras sofrem ofensas relacionadas à aparência delas, além de serem referidas como "vadia", "vagabunda". Outros pesquisadores como Menti e Araújo (2017) também explicam, em seu estudo, que entre as frases mais ouvidas por mulheres durante os jogos algumas delas seriam "vadia", "vagabunda" e "gorda", ratificando a observação de que nas interações entre os jogadores, 
nos games e nos sites de redes sociais, indivíduos do gênero feminino são agredidos por meio de insultos, sobretudo relacionados à sua aparência e conduta.

A quinta e última forma de manifestação de violência simbólica de gênero encontrada nas interações analisadas foi a questão do assédio sexual. Tal tipo de agressão pode ser observado de modo mais claro na publicação 3 (quadro 1), em que uma menina denuncia um jogador que oferece pontos do jogo League of Legends no Facebook e que, por meio de bate-papo no aplicativo Messenger, esclarece que tais pontos somente seriam concedidos em troca de fotos dela nua.

Esse tipo de comportamento presente nas interações em jogos de combate e sobre eles nas mídias sociais também é entendido como violência e observado por Kurtz (2015), que afirma que um dos tipos de agressões sofridas pelas mulheres em games tipicamente tidos como masculinos é o oferecimento de dinheiro em troca de fotos delas com conteúdo de nudez e o envio de desenhos obscenos.

\section{Considerações gerais}

Com base nas discussões teóricas e nos dados apresentados na presente pesquisa, é possível compreender que a participação feminina em jogos eletrônicos de combate não é um ponto pacífico nesse contexto. Enquanto o gênero masculino ocupa uma posição privilegiada, sendo os homens considerados como aqueles que detêm o capital simbólico necessário para obterem sucesso nos games, como agressividade e liderança, às mulheres são atribuídas características como fragilidade e inabilidade para lidar com computadores, assim como com tarefas que envolvam desenvolver estratégias e agir com liderança, em acordo com os trabalhos de Olegário (2009) e Cross (2014).

Pode-se observar que, embora as publicações sobre a participação feminina nos games não sejam as mais frequentes nas páginas e grupos sobre jogos eletrônicos, quando elas são encontradas, é possível observar comentários que visam manter o status quo, isto é, o discurso, nesses casos, é entendido como um instrumento de poder (FOUCAULT, 2014; BOURDIEU 1989, 1991) que tem por objetivo que o gênero feminino permaneça em uma posição histórica de invisibilidade, restrito a tarefas domésticas e de menos destaque (PERROT, 2017). Quanto aos games, há a tentativa de que os homens continuem sobrepondo-se em número nas partidas assim como em funções tidas como mais importantes por outros participantes.

Tal discurso, conforme abordado nesta pesquisa, é um objeto de dominação que desvaloriza e deprecia a mulher, sendo entendido, desse modo, como violência simbólica (ZIZEK, 2014), apesar de não ser considerado como tal por membros da página e grupos observados devido a um processo histórico de naturalização, que fez com que tais construções sejam consideradas como verdades (BOURDIEU, 1989). Devido a tal percepção, 
inclusive por parte das vítimas, essas ideias acabam, portanto, se reafirmando e ganhando força nos ambientes online.

Por meio da investigação feita através da Análise de Discurso Mediado por Computador (HERRING, 2004), foi possível observar que, nas seis publicações estudadas, se observa cinco maneiras pelas quais tal violência simbólica direcionada ao gênero feminino se manifestou. Em primeiro lugar, por ordem de ocorrências, houve a tentativa de calar as denúncias de agressões por meio da interdição da fala das jogadoras (FOUCAULT, 2014), sendo essas taxadas de loucas, exageradas e de pessoas que tinham como único objetivo chamarem atenção sobre si mesmas. Em segunda posição, foram encontrados estereótipos, reforçados por discursos misóginos construídos historicamente sobre o papel do gênero feminino, que buscavam evidenciar o quanto inadequadas as meninas eram com relação aos jogos de combate.

A seguir, observou-se a questão da culpabilização das vítimas em que foi atribuída às mesmas a culpa por ofensas direcionadas a elas também por casos de assédio sexual, sendo estes representados como algo natural praticado pelo gênero, conforme abordado por Bourdieu (1991) quanto trata da transformação de certos discursos em verdades. Nesses casos, caberia a quem sofreu com isso apenas reconhecer o ato e recusar a proposta. Por fim, na quinta forma de violência, verificou-se assédio sexual, por meio de proposta de favores em troca de fotos que envolviam nudez, algo, igualmente, observado no projeto de Kurtz (2015) e que visa obter proveito das jogadoras e não as incentivar a se manterem no jogo.

Entende-se que a análise desses tipos de comentário é de suma importância, pois auxilia no entendimento de que estratégias discursivas são utilizadas para manter como senso comum verdades que favorecem o lado dos que estão em posição privilegiada, nos casos em questão, o gênero masculino. Levando isso em consideração, é possível compreender que estudar e debater a questão da violência simbólica de gênero e as suas possíveis manifestações - interdição da fala do outro, estigmas, culpabilização da vítima, insultos e assédio sexual - é essencial a fim de se repensar discursos excludentes que se naturalizaram ao longo da história por meio das relações de poder tanto no ambiente dos jogos eletrônicos de combate quanto em outros contextos de comunicação.

\section{Referências}

ALMEIDA, Lenildes Ribeiro Silva. Pierre Bourdieu: A transformação social no contexto de "A Reprodução". INTER-AÇÃO. Revista da Faculdade de Educação, Editora da UFG, Goiânia, v. 30, n. 1, p. 139-155, 2005.

BARBOZA, Eduardo; SILVA, Ana Carolina. A evolução tecnológica dos jogos eletrônicos: do videogame para o newsgame. In: 5o Simpósio Internacional de Ciberjornalismo, 2014. Campo Grande. Anais... Campo Grande: UFMS, 2014. p. 1-16. 
BOURDIEU, Pierre. O Poder Simbólico. Rio de Janeiro: Bertrand Brasil, 1989.

BOURDIEU, Pierre. Language and Symbolic Power. Massachusetts, Harvard University Press, 1991.

BOURDIEU, Pierre. A dominação masculina. 9. ed. Rio de Janeiro: Bertrand Brasil, 2010.

CASSELL, Justine; JENKINS, Henry (Ed.). From Barbie to Mortal Kombat: gender and computer games. MIT press, 2000.

CROSS, Katherine. Ethics for cyborgs: On real harassment in an "unreal" place. Loading... The Journal of the Canadian Game Studies Association, v. 8, n. 13, p. 4-21, 2014.

FOUCAULT, Michel. A ordem do discurso: aula inaugural no Collège de France, pronunciada em 1970. 3. ed. São Paulo: Edições Loyola, 1996.

FRAGOSO, Suely; RECUERO, Raquel; CAETANO, Mayara. Violência de gênero entre gamers brasileiros: um estudo exploratório no Facebook. Lumina, v. 11, n. 1, p. 1-21, 2017. https://doi.org/10.34019/1981-4070.2017.v11.21367

HERRING, Susan. Computer-mediated discourse analysis: An approach to researching online behavior. In: BARAB, S. A.; KLING, R.; GRAY, J. H. (Eds.). Designing for Virtual Communities in the Service of Learning. New York: Cambridge University Press, 2004. p. 338-376. https://doi.org/10.1017/CB09780511805080.016

KURTZ, Gabriela Birnfeld. "Se tiver meninas, melhor ainda": análise da participação feminina no jogo Dota 2 no Brasil. In: XXXVIII Congresso Brasileiro de Ciências da Comunicação, Intercom. Rio de Janeiro, RJ, 2015. p. 1-15.

MENTI, Daniela Cristina; ARAÚJO, Denise Castilhos de. Violência de gênero contra mulheres no cenário dos eSports. Conexão - Comunicação e Cultura, v. 16, n. 31, p. 73-88, 2017. https://doi.org/10.18226/21782687.v16.n31.03

OLEGÁRIO, Maria da Luz; LIMA, Rosângela de Araújo; BORGES, Leónidas Leão. Games e violência em uma perspectiva de gênero. Debates em educação, v. 1, n. 1, p. 1-12, 2009.

PERROT, Michelle. Minha história das mulheres. Tradução Angela M. S. Côrrea. 2. ed., 5. reimpressão. São Paulo: Contexto, 2017.

RECUERO, Raquel; SOARES, Pricilla. Violência simbólica e redes sociais no Facebook: o caso da fanpage "Diva Depressão". Galáxia (São Paulo, Online), n. 26, p. 239-254, 2013. https://doi.org/10.1590/S1982-25532013000300019

SCOTT, Joan. Gênero: uma categoria útil de análise histórica. Educação \& Realidade, Porto Alegre, v. io, n. 2, p. 71-99, 1995.

STOLZ, Sheila. A ordem do discurso e suas relações com o poder: vertigem e quebra de certezas. JURIS, Rio Grande, v. 13, p. 159-176, 2008.

VIEGAS, Paula; RECUERO, Raquel. Violência simbólica de gênero na publicidade digital. In: XXXVII Congresso Brasileiro de Ciências da Comunicação, Foz do Iguaçu, PR, 2014. p. 1-15.

ZIZEK, Slavoj. Violência: seis reflexões laterais. São Paulo: Boitempo, 2014.

Recebido em: 29/09/2019.

Aceito em: 29/03/2020. 